\title{
La economía mexicana en \\ la era de la globalización
}

Sergio

Vallejos Ortiz

CEPE-UNAM

INTRODUCCIÓN. POLÍTICA Y ECONOMÍA EN PERSPECTIVA

Desde el siglo XVI, con el surgimiento de la Edad Moderna, el mundo comienza un proceso creciente de desarroIlo político y militar, que culmina con el establecimiento del Estado-nación a escala mundial. Para 1914 literalmente, todos los territorios del planeta son parte del sistema mundial de naciones. No quedaban ya poblaciones aisladas ni territorios sin conquistar.

La evolución del mundo que colonizaron los primeros seres humanos que salieron de África hace apenas unos 50 mil años, al mundo fragmentado de la modernidad, es obra de un delicado proceso interactivo: el poder militar que defendía a los puebl os de posi bles agresores externos y abría mercados de bienes estratégi cos hacia fuera, también estableció políticas de control hacia adentro.

En la medida que los estados vecinos se integraron y consolidaron, el entorno político se volvía más agresivo y era imprescindible desarrollarse y crecer también, a riesgo de terminar como una colonia sin derechos sobre la nueva metrópoli o en su defecto y con un poco de suerte, en una nación aislada y pobre.

La gráfica 1 muestra una clara tendencia ascendente en el número de seres humanos muertos en las guerras desde finales del siglo XV, Ilegando a un punto máximo en la primera mitad del siglo XX.

El mercantilismo económico que surge de las instituciones municipal es de la Edad Media tiene como objeto, imponer políticas económicas, ahora, a escal a nacional.

La competencia por territorios y recursos, se hizo importante, una vez que la productividad aumenta con la Revolución industrial del siglo XIX y el abasto de materias primas y en general de insumos no producidos por cada país, es una condición estratégica para garantizar el cre- 
Gráfica 1 Seres humanos muertos en guerras Muertos en guerras en periodos de cincuenta años

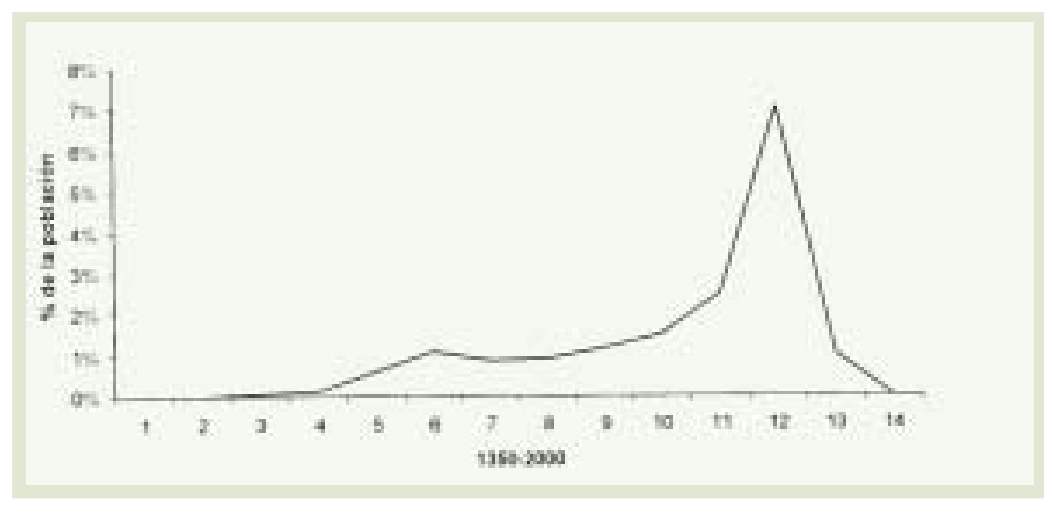

Fuente: Cálculos propios con datos de Development Centre Studies (2006) y Wikipedia.

cimiento económico que antes no existía, y ahora, además de ser posible, es necesario.

Tanto el mercantilismo como su posterior evolución en imperialismo, tienen muy claro que en el contexto internacional es un juego de ganar-perder.

\section{LAS GUERRA MUNDIALESY EL INICIO DE LA GLOBALIZACIÓN ECONÓMICA}

No exageramos si decimos que la historia de la modernidad es la historia de la guerra. Como tampoco casual que este proceso haya generado dos guerras de escal a verdaderamente mundial. Antes de la Edad Moderna, Ias guerras sol o tenían repercusión regional. Ahora el mundo es una compleja red de intereses y pactos militares.

Sin desconocer la existencia de etapas de crecimiento en la migración y el comercio internacional en algunos lapsos cortos de la historia, las dos guerras mundiales revelan con contundencia que la primera globalización total es política.

¿Qué significado habrán tenido las guerras de exterminio imperialista, el Gulag soviético, el holocausto nazi, las bombas nucleares, ( 150 años después de la promulgación de los Derechos del Hombre), para la tradición histórica marxista hegeliana por ejemplo, que suponía que 
Ia humanidad evolucionaba dialécticamente en forma siempre ascendente?

Era muy claro que este proceso no podía continuar más, la humanidad había tocado fondo y el mundo empezó a cambiar.

Las dos grandes potencias ganadoras, Estados Unidos y la Unión Soviética, eran países muy grandes, con vastos recursos natural es, sin necesidad de posesiones coloniales por lo que no estaban demasiado interesadas en expandirse territorial mente a cual quier costo.

La Guerra fría nos habla de que más allá de la retórica, ninguna parte estaba interesada en una guerra "cal iente" que podría ser la última.

En Occidente, y dado que Estados Unidos mantuvo papel defensivo casi en exclusiva, el poder militar disminuye en casi todos los países y las democracias florecen.

Esto significaba un mundo menos hostil y por primera vez desde la Edad Media, el proceso del poder militarnacional empezó a desquebrajarse. Nunca antes desdeel sigl o XVI habíamos tenido un periodo tan largo de paz entre potencias principales, pero tampoco, nunca antes habían existido tantos países derrotados contundentemente en una guerra, los cuales crecieron a un ritmo superior que los vencedores. J apón y Alemania, se convierten en apenas 30 años - después de terminada la guerra—- en la segunda y tercera economías del mundo, ambas basadas en una potente industria exportadora, inversamente proporcional a su liderazgo político.

La gráfica 2, muestra como a partir del fin de la Segunda Guerra Mundial el comercio internacional crecea tasas al tas y constantes en paral elo a la disminución de seres humanos muertos en guerras de la gráfica 1 .

Contra cierta creencia generalizada, el comercio internacional no crece a mayores tasas en los años 80 y 90 cuando se acuña el término globalización. Quizá lo que sucedió es que en ese momento se identificó la fuerza y permanencia de este proceso. 
Gráfica 2. Evolución del comercio internacional

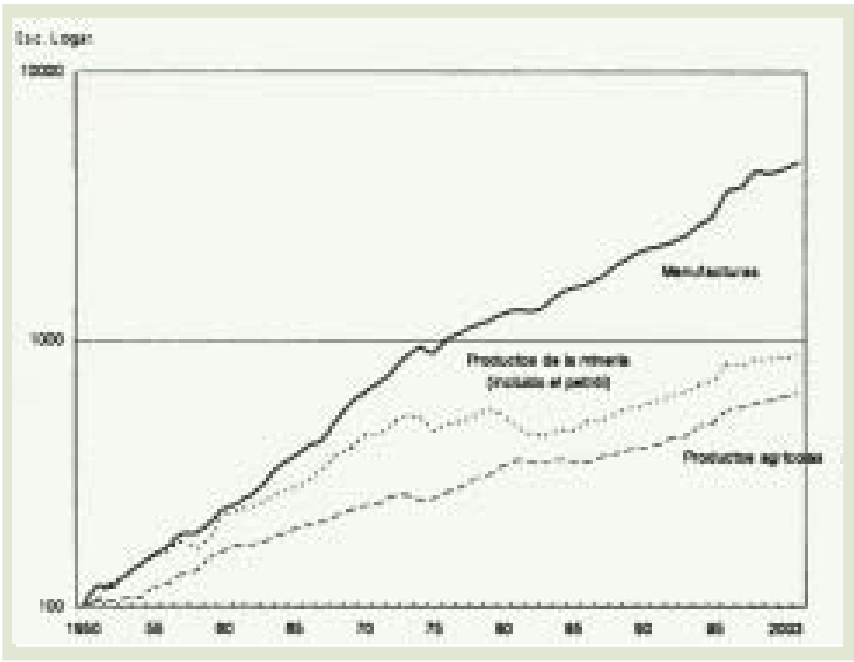

Fuente: Cálculos propios con datos de Development Centre Studies (2006)

y Wikipedia.

Aquell os países que de al guna manera se aferraron al antiguo model o colonial, empezaron a perder poder económico relativo.

Casi todos los países de África y Asia se independizaron y comienzan a integrarse a la economía mundial, no sin antes pasar por un periodo conflictivo, que podemos Ilamar de consolidación nacional.

Los procesos de apertura reciente de China y la I ndia son ejemplos de ello.

La inesperada caída del bloque comunista y de la Unión Soviética en 1992, fue un hecho también novedoso; en realidad, no hubo una victoria militar ni política de Estados Unidos. Simplemente la contraparte comunista se desplomó por sus propias contradicciones y no fue sojuzgada por el capitalismo como al gunos afirman.

El hecho, es que este espectacular derrumbe, contribuyó a un ambiente de mayor cooperación internacional que detonó lo que se conoce como la Revolución liberal de los noventa.

Lentamente el espacio que empezó a perder el poder político lo fue ganando el poder económico. 
EL TEOREMA DE IMPOSIBILIDAD DE ARROW Y SEN Y EL MERCADO

La Teoría de la Elección Social nos dicen que: Ios Marcos de Decisión Colectiva que la política supone, tienen problemas para convivir con sociedades cada vez más plurales y cada vez más democráticas.

El famoso Teorema de imposibilidad de Arrow ${ }^{1}$ establece la exclusión entre racionalidad colectiva y democracia. Entre más coherencia exigimos a un sistema político, es menos probable que pueda ser democrático.

Mientras que en su famoso artículo “La imposibilidad de un liberal paretiano"2 Sen establece la imposibilidad de un sistema de elección colectiva para permitir incluso una sola decisión individual, cuando existen diferencias importantes en los val ores individuales.

Para que florezcan los derechos individuales y la democracia, es necesario disminuir la cobertura de las decisiones colectivas, mejor conocidas como política.
1 Keneth J. Arrow, Social Choices and Individual Values.

2 Amarya K. Sen, "La imposibilidad de un liberal paretiano", en Journal of Political Economy, núm. 78, pp. 152-157.

Gráfica 3. Democracia

Número de países con clasificación superior a8según la Política IV

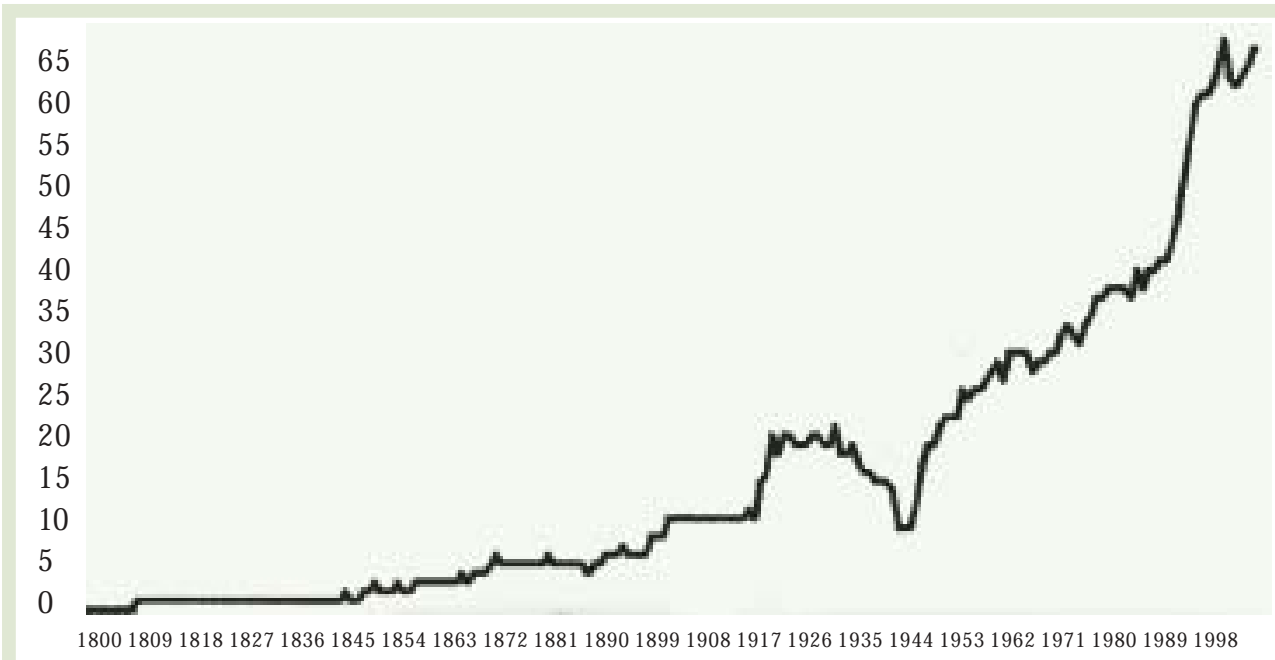

Fuente: Center of Internacional Development and Conflict Management.

Pero así como la teoría de la Elección Social establece lo conflictivo de los Marcos de Decisión Colectiva, su enorme dificultad para establecer situaciones ganar-ga- 
nar y por ende equilibrios paretianos, la Teoría del Equilibrio General, en su desarrollo final conocido como model o Arrow-Debreu, nos dice lo contrario para los Marcos de Decisión Individual. El equilibrio simultáneo para todos los bienes es posible y este es paretiano.

La gráfica 3, muestra que paralelo al desarrollo del comercio internacional, los sistemas democráticos se generalizan después de los años 40 del siglo Xx.

Hayek, decía que la única forma posible para que una democracia sea exitosa es que no se intrometa demasiado en las decisiones de la gente. Los totalitarismos colectivos fueron diseñados para la guerra hacia el exterior y para la homogeneidad hacia el interior.

El sistema de mercado complejo y diverso de la actualidad, no se puede desarrollar en estos sistemas. Sol o florece dentro de los Marcos de Decisión Individual, quela democracia protege y permite.

No es casual que sea justamente después de la Segunda Guerra Mundial, en los años 60 del siglo XX cuando surge la gran revolución cultural: Ias mujeres adquieren el derecho al voto, los derechos civiles, la li bertad sexual, entre otros, se generalizan.

Las decisiones importantes para la vida de las personas se toman cada vez más a escala personal y dependen menos del aparato político militar.

Se consolida un proceso en el que los ciudadanos de casi todos los países democráticos desconfían de sus gobernantes, la militancia en partidos políticos y sindicatos se desploman y la participación en organizaciones lúdicas de participación voluntaria se dispara.

\section{MÉXICO: DEL NACIONALISMO A LA APERTURA}

España es la nación que inaugura en el siglo XVI, la etapa del colonialismo moderno.

La Nueva España es su colonia más importante y desde entonces nuestra historia está conectada al sistema mundial de naciones irremediablemente.

Con la consumación dela I ndependencia, México padece una difícil situación de debilidad en un mundo crecien- 
temente hostil, pero con la llegada de la Doctrina Monroey la impresionante expansión económica deEstados Unidos, todo el continente americano queda de al guna manera vacunado contra el imperialismo europeo y logra cierta independencia de los acontecimientos mundiales.

A partir de los años 20 del siglo pasado, el sistema político postrevolucionario se consolida logrando una estabilidad y permanencia casi única en el mundo. La ideología revolucionaria fue flexible e imprecisa, sustentada en el nacionalismo como en la mayor parte de los países de la época, con la diferencia que México no tenía enemigos externos creíbles, capaces de generar una carrera militarista.

Incluso en la peor etapa del imperialismo, Lázaro Cárdenas logra nacionalizar el petróleo sin mayores contratiempos con Estados Unidos o la Gran Bretaña.

Esta relativa estabilidad permitió aprovechar la Segunda Guerra Mundial como ocasión para iniciar la industrialización del país dentro del Ilamado sistema de sustitución de importaciones.

Tenemos progreso y paz, hasta que este model o hace crisis durante los años setenta y ochenta, justo cuando el poder político llega a su máxima expansión.

En 1976, el Partido Revolucionario Institucional (PRI) gana la presidencia con el 100 por ciento de los votos válidos. El punto de inflexión en consonancia con varios países en vías de desarrollo seguramente comienza hasta esos años.

La tabla 1 muestra como es en los años 80 comienza la apertura comercial de México quesedisparaa partir de 1994.

Tabla 1-México. Comercio internacional 1950-2005

\begin{tabular}{|llllllllllll|} 
& 1950 & 1960 & 1970 & 1977 & 1980 & 1985 & 1990 & 1994 & 1998 & 2001 & 2005 \\
\hline Exportaciones & 497 & 738 & 1,289 & 4,649 & 18,131 & 29,101 & 40,711 & 60,882 & 117,500 & 145,000 & 240,000 \\
Importaciones & 555 & 1,186 & 2,329 & 5,704 & 21,208 & 15,915 & 41,592 & 79,346 & 125,246 & 152,000 & 247,000 \\
PIB & 14,880 & 24,238 & 35,541 & 66,944 & 192,175 & 127,049 & 250,473 & 266,416 & 384,112 & 444,658 & 690,000 \\
habitantes & 25,791 & 34,923 & 48,225 & 61,980 & 69,660 & 77,940 & 82,590 & 93,010 & 100,240 & 104,818 & 106,567 \\
(miles) & & & & & & & & & & & \\
exp+imp/PIB(\%) & $7.07 \%$ & $7.94 \%$ & $10.18 \%$ & $15.47 \%$ & $20.47 \%$ & $35.43 \%$ & $32.86 \%$ & $52.63 \%$ & $63.20 \%$ & $66.79 \%$ & $70.58 \%$ \\
exp/ hab & 21.52 & 33.96 & 48.29 & 92.03 & 304.45 & 204.20 & 503.60 & 853.09 & $1,249.46$ & $1,450.13$ & $2,317.79$ \\
(usd/persona) & & & & & & & & & & & \\
\end{tabular}


Paral elamente a este crecimiento, y no menos importante que el anterior, se registra una profunda transformación del sistema político mexicano.

La oposición empieza a lograr más espacios hasta logar la mayoría en la Cámara de Diputados y la Presidencia de la República en 1997 y 2000 respectivamente.

El poder judicial comienza a independizarse del poder político. Se generalizan los organismos públicos independientes con innegable éxito y prestigio, como el Instituto Federal Electoral (IFE), el Banco de México o la Comisión Nacional de Derechos Humanos (CNDH).

En los años 70 por ejemplo fueron comunes frases como "ahora la economía se maneja desde Los Pinos" dicha por el entonces presidente Luis Echeverría o "defenderé el peso como un perro"por el presidente López Portillo. Mostraban como la economía estaba supeditada a la política.

Tuvimos crisis cambiarias graves en 1976, 1982 y 1994. No deja de ser significativo que en México la llegada de la democracia significó la liberalización del tipo de cambi y la independencia del Banco de México. El poder político pierde atributos y sale de la macro economía. Ahora el tipo de cambio lo fija el mercado y la emisión monetaria es neutra.

Huelga decir que con ello desaparecieron las crisis macroeconómicas, principal causa de pobreza e inequidad en años recientes. Nunca antes las tasas de interés, tipo de cambio, inflación habían estado tan estables, la deuda externa tan manejable, no obstante el tamaño y grado de complejidad de la economía mexicana actual.

El gobierno deVicente Fox, más bien fuecriticado, -y no sin razón-, por evadir responsabilidades que antes el presidente de la República asumía sin problema, el "y yo porqué", muestralimitaciones y carencias, pero no intromisión.

Ahora la economía marca el paso a la política. 
CONCLUSIÓN. LA ECONOMÍA, DE LA SOCIOLOGÍA A LA SICOLOGÍA

Las tres cuartas partes de las necesidades que existen en el mundo son románticas, basadas en visiones, ideal ismos, esperanzas y afectos; y regular el bolsillo es esencialmente regular la imaginación y el corazón. En consecuencia, la correcta discusión de la natural eza de los precios es un problema sumamente metafísico y psíquico.

(J ohn Ruskin, Unto This Last)

La globalización económica es un proceso más profundo de lo que muchas veces se cree. Surge de las cenizas de la Segunda Guerra Mundial y ha envuelto a México desde un inicio y no es probable que cambie.

No es un fenómeno político. Ningún gobierno ni poder militar la impone. Más bien surge del resquebrajamiento del poder político del estado. Explica la relación entre disminución del poder militar, aumento dela democracia y del comercio internacional.

Su enorme fuerza radica en la voluntad individual de miles de millones de personas que interactúan entre sí todos los días con el único ánimo de lograr satisfacción subjetiva, y ser felices.

Por primera vez desde el inicio de la modernidad, los acontecimientos importantes se escriben a escala individual. Ya no son las grandes gestas y batal las que llenaron de monumentos y arcos del triunfo las ciudades, Ias que importan.

Las contradicciones ideológicas son comunes, en una ambientegeneral marcado por políticas públ icas pragmáticas.

Hay gente que dice que todos los partidos gobernantes son de centro.

En realidad es sólo una forma de llamarle a la no ideología que ha impregnado a casi todos los gobiernos a incluso de países no democráticos como China, que se han enfocado más en atender problemas concretos de la gente y menos en lograr posturas retóricas que buscan arengar a la masas hacia paraísos utópicos inexistentes como en el pasado.

Aunque hay teorías sólidas que la estudian, la global ización, al no ser un fenómeno colectivo no requie- 
re un marco ideológico para su funcionamiento. Funciona mejor en contextos de cambio y subjetividad.

Pero quizá más representativo de este Nuevo Orden en gestación, que el aumento vertiginoso del comercio internacional, son por ejemplo, las reformas legales recientes en México, como la posibilidad de las sociedades de convivencia para parejas homosexuales, la despenalización del aborto y de ciertas formas de eutanasia en el Distrito Federal.

Son todas ellas manifestaciones de lo poco tolerantes que nos hemos vuel to para aceptar que el otro intervenga en decisiones que deben tomarse en la intimidad.

BIBLIOGRAFÍA

ARROW KenETH, J ., Social Choice and Individual Values, Cowles Foundation. New York, 1951.

BECKER GARY, Habits, Adictions, and Traditions. KIKLOS, vol.45, 1991.

Development Centre Studies, oecD, The World Economy, vol. A Millennial Perspective, vol. II Historical Statistics, 2006.

FUKUYAMA, Francis, El Fin de la Historia y el último Hombre. Madrid, Anagrama, 1992.

OMC, Evolución de Comercio Mundial, 2003.

SEN AMARTYA, K., Elección Colectiva y Bienestar Social. Madrid, Alianza Editorial, 1970.

-, "La imposi bilidad de un liberal paretiano", en J ournal of Political Economy, núm. 78, 1970. 